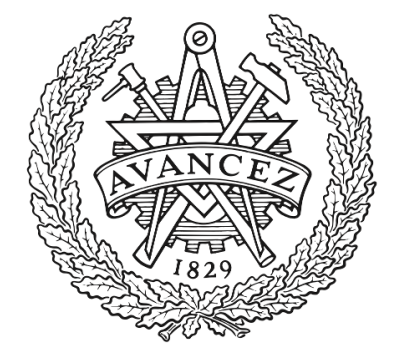

\title{
CHALMERS
}

UNIVERSITY OF TECHNOLOGY

\section{Monitoring and Interpreting the Early Properties of Alkali-Activated Materials by Electrical Conductivity Measurement}

Downloaded from: https://research.chalmers.se, 2023-04-26 10:24 UTC

Citation for the original published paper (version of record):

Tang, L., Liu, J., Zhang, E. (2020). Monitoring and Interpreting the Early Properties of Alkali-Activated Materials by Electrical

Conductivity Measurement. RILEM Bookseries: 349-355.

http://dx.doi.org/10.1007/978-3-030-22034-1_39

N.B. When citing this work, cite the original published paper. 


\title{
Monitoring and Interpreting the Early Properties of Alkali-Activated Materials by Electrical Conductivity Measurement
}

\author{
Luping Tang ${ }^{1}$, Jun $\mathrm{Liu}^{2}$ and Emma Zhang ${ }^{1}$ \\ ${ }^{1}$ Chalmers University of Technology, SE-412 96 Gothenburg, Sweden \\ ${ }^{2}$ Shenzhen University, Shenzhen, China \\ tang. luping@chalmers.se
}

\begin{abstract}
Alkali-activated materials are attracting more and more attention worldwide thanks to their low carbon footprint. Different from the binders based on ordinary Portland cement, the early properties such as flowability, setting, and early strength development, of alkali-activated materials can vary very much and are very sensitive to the compositions of concrete mixture. Conventional methods for testing such early properties are often time-consuming and laborious, whilst the measurement of electrical conductivity is relatively simple and can easily be monitored in an automatic manner. This paper presents a simple monitoring technique based on Winner's resistivity method and some results measured from mortar samples with various compositions of alkaliactivated materials as well as ordinary Portland cements. The preliminary results show some reasonable correlations between monitored conductivity curves and measured/observed early properties. Some interpretations and theoretical considerations to these measured conductivity curves in relation to the early properties and possible chemical reactions are discussed.
\end{abstract}

Keywords: Alkali-Activated Materials, Early Properties, Conductivity.

\section{Introduction}

In the past decades, alkali-activated materials are attracting more and more attention worldwide thanks to their low carbon footprint as well as their versatility in applications and adoptability to locally available raw materials [1]. Different from the binders based on ordinary Portland cement, the early properties such as flowability, setting, and early strength development, of alkali-activated materials can vary very much and are very sensitive to the compositions of concrete mixture. Conventional methods for testing such early properties are often time-consuming and laborious, whilst the measurement of electrical conductivity or resistivity is relatively simple and can easily be monitored in an automatic manner. At present, there is at least one standard method available for testing the surface resistivity of hardened concrete [2], but up to now no standard method available for testing the resistivity of fresh concrete, probably due to the contact problem between electrodes and concrete. Li et al. [3] devel- 
oped an innovative non-contacting device for measuring resistivity of fresh concrete without the contact problem. Their method has been used for determination of concrete setting time [4] and for improving understanding of cement hydration mechanism [5]. Wei et al. [6] used this technique to investigate the effect of superplasticizer on the setting time. However, this non-contacting method need a special device which is not available in ordinary laboratories. On the other hand, the study of fresh alkaliactivated materials using the technique of electrical resistivity is limited. This paper presents a simple monitoring technique based on Winner's resistivity method for monitor the resistivity profiles of mortar samples with various compositions of alkaliactivated materials as well as ordinary Portland cements.

\section{Experimental}

\subsection{Setup for resistivity measurement}

The experimental setup for each sample consists of a test cell, a galvanostatic pulse generator, and a potential recorder (datalogger). The test cell is made of PVC plastic with four stainless steel screws equally distributed $(a=25 \mathrm{~mm})$ on the bottom (Fig. 1) for resistivity measurement based on Winner's four-electrodes method, which can effectively eliminate the influence of contact resistance when compared with twoelectrodes method. Instead of alternative current, a galvanostatic pulse of $0.2 \mathrm{~mA}$ at about 0.1 seconds was used in this study for avoiding the effect of polarization on the potential measurement. The potentials were recorded by a datalogger (Campbell CR10) at an interval of 1-2 minutes in the first 24 hours and 10 minutes for the hydration period over one day.
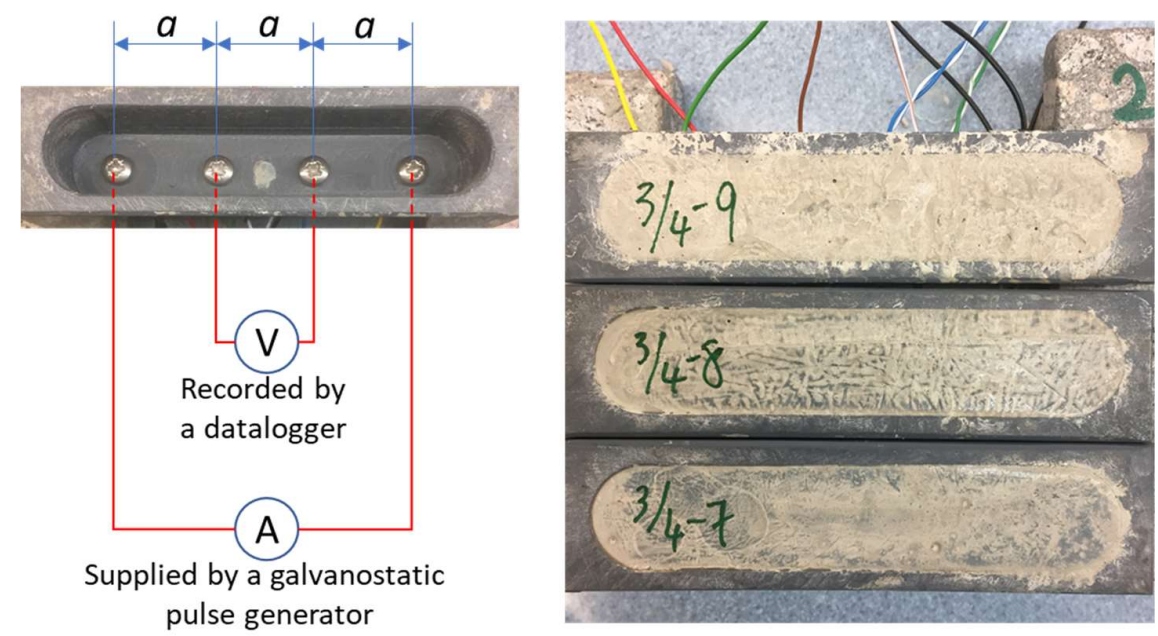

Fig. 1. Setup for resistivity measurement (left) and samples after hardened (right). 


\subsection{Mixtures and test procedure}

In this study Swedish cement named "Bascement Slite" (CEM II/A-V $52.5 \mathrm{~N}$ according to European standard EN 197-1) and ground granulated blast furnace slag named "Merit 5000" (specific surface area $5000 \mathrm{~cm}^{2} / \mathrm{g}$ and density $2920 \mathrm{~kg} / \mathrm{m}^{3}$ ) were used as cementitious materials. The main chemical compositions of the cementitious materials are listed in Tab. 1. Natural quartz sand of $0-2 \mathrm{~mm}$ was used as aggregate to improve the homogeneity of mixes. The water glass $\left(\mathrm{Na}_{2} \mathrm{O} \cdot n \mathrm{SiO}_{2}\right)$ with initial modulus $n=3.35$ (molar ratio $\mathrm{SiO}_{2} / \mathrm{Na}_{2} \mathrm{O}$ ) (supplied by Sibelco Nordic) was adjusted by addition of $\mathrm{NaOH}$ (analytical grade, purchased from Fisher Scientific) to $n=1.2$ and used as alkali-activator. Gypsum $\left(\mathrm{CaSO}_{4} \cdot 2 \mathrm{H}_{2} \mathrm{O}\right.$, puriss grade, purchased from Fisher Scientific) was used with the purpose for reducing shrinkage in some mixes. The mixes tested in this study are listed in Tab. 2. In all the mixes the ratio of water to binder (cement + slag) was fixed at 0.5 and the ratio of sand to binder fixed at 1 . The mixing procedure was in accordance with EN 196-1 and the initial setting time was measured by a Vicat (Toni Technik) with a calibrated weight of $300 \mathrm{~g}$ and a cylindrical needle with a flat tip area of $1 \mathrm{~mm}^{2}$. The mortar sample for the initial setting time test was 40 $\mathrm{mm}$ thick and filled in a plastic cup of diameter about $50 \mathrm{~mm}$. The penetration depth was measured in a certain time interval of 5-10 minutes until the reading $(6 \pm 3) \mathrm{mm}$ was reached when compared with the initial reading (zero).

Table 1. Main chemical compositions of slag Merit 5000.

\begin{tabular}{lcccccccccc}
\hline & $\mathrm{CaO}$ & $\mathrm{SiO}_{2}$ & $\mathrm{Al}_{2} \mathrm{O}_{3}$ & $\mathrm{Fe}_{2} \mathrm{O}_{3}$ & $\mathrm{MgO}$ & $\mathrm{TiO}_{2}$ & $\mathrm{Mn}_{2} \mathrm{O}_{3}$ & $\mathrm{~S}^{2-}$ & $\mathrm{SO}_{3}$ & $\mathrm{Na}_{2} \mathrm{O}-\mathrm{eq}$ \\
\hline Cement & 56.7 & 22.7 & 6.1 & 3.6 & 2.9 & & & & 3.4 & 1.1 \\
\hline Slag & 31 & 34 & 13 & & 17 & 2.4 & 0.8 & 1.3 & 0.25 & 0.9 \\
\hline
\end{tabular}

Table 2. Mix proportions of mortar samples normalized by the binder (cement + slag) weight.

\begin{tabular}{lcccccc}
\hline Mix No. & \multicolumn{2}{c}{ Binder } & Gypsum & \multicolumn{2}{c}{ Activator } & Initial setting time \\
& Cement & Slag & & $\mathrm{Na}_{2} \mathrm{O}$ & $\mathrm{SiO}_{2}$ & (minutes) \\
\hline BasC & 1 & & & & & $150^{*}$ \\
AAS80-1 & 0.2 & 0.8 & & 0.048 & 0.0557 & 220 \\
AAS80-2 & 0.2 & 0.8 & 0.02 & 0.048 & 0.056 & 190 \\
AAS80-3 & 0.2 & 0.8 & 0.04 & 0.048 & 0.056 & 90 \\
AAS80-4 & 0.2 & 0.8 & & 0.052 & 0.0604 & 220 \\
AAS80-5 & 0.2 & 0.8 & 0.02 & 0.052 & 0.0604 & 180 \\
AAS80-6 & 0.2 & 0.8 & 0.04 & 0.052 & 0.0604 & 160 \\
AAS100-1 & & 1 & & 0.065 & 0.0755 & 40 \\
AAS100-2 & & 1 & 0.02 & 0.065 & 0.0755 & 35 \\
AAS100-3 & & 1 & 0.04 & 0.065 & 0.0755 & 30 \\
\hline
\end{tabular}

* setting time supplied by the manufacturer. 


\section{$3 \quad$ Results and discussions}

According to Winner's four-electrodes method the resistivity $\rho$ is calculated by the following equation:

$$
\rho=\frac{2 \pi a \Delta U}{I}
$$

where $a$ is the distance between the electrodes, $\Delta U$ is the recorded potential, and $I$ is the impressed galvanostatic current. To facilitate the discussion, conductivity $\sigma-$ the inverse of resistivity, was used in this study for expressing the results.

\subsection{Conductivity curves of the samples with ordinary Portland cement}

Fig. 2 shows the conductivity curves recorded from the samples mixed with ordinary Portland cement. It can be seen from Fig. 2 that, although there is a certain deviation in the absolute values of conductivity, the curves expressed by $\sigma \cdot t$ from three samples are generally comparable, indicating an acceptable repeatability of the measurement method. It seems difficult to correlate the setting time to the changes in conductivity, although the latter dramatically decreased with the time after mixed for 6-12 hours, with the first peek at 7-8 hours and the second peak at 11-12 hours. These peeks indicate structural changes in the matrix due to the accelerated hydration.

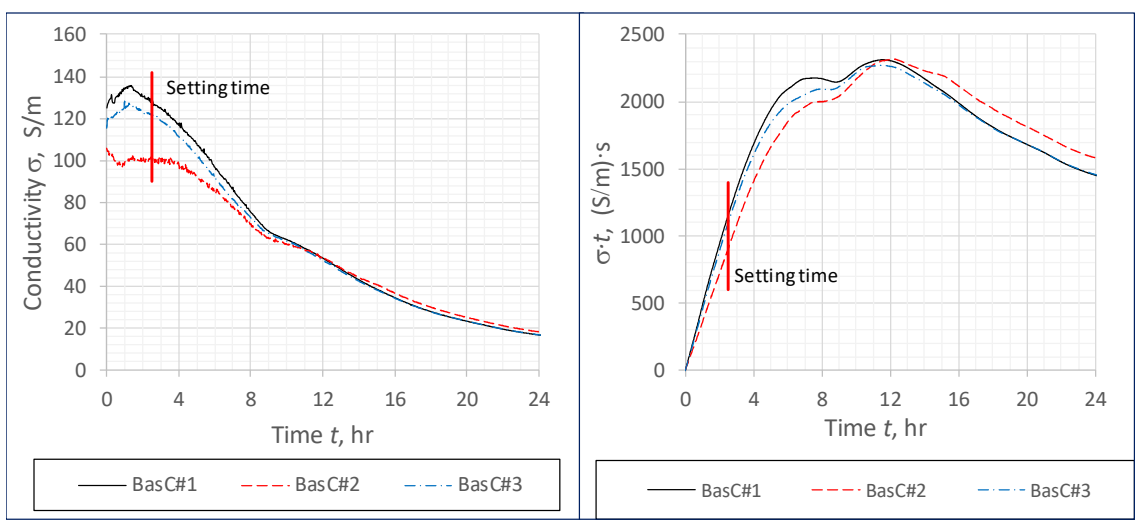

Fig. 2. Conductivity curves from the ordinary Portland cement samples.

\subsection{Conductivity curves of the samples with alkali-activated slag}

Fig. 3 shows the conductivity curves recorded from the samples mixed with $100 \%$ slag. The conductivity curve for AAS100-3 markedly decreased in the first hour and increased again in the followed hour. The addition of gypsum probably changed the ionic concentrations in the mixing water. The measured setting time in this group of samples is relatively short, only 30-40 minutes. It was observed that, in the first 20-30 minutes the mixes were very flowable, but suddenly became hardened. The peeks of $\sigma \cdot t$-curves are, however, in the range of $8-9$ hours, implying the reduction of pore 
solutions due to the formation of solid network. This means that the early setting may not be due to the formation of hydration products but possibly be caused by some type of gelling. It seems that the addition of gypsum has no clear effect on the hydration process in the mixes with $100 \%$ slag, probably due to the less availability of calcium ions for the formation of ettringite or less solubility of gypsum in the high alkaline condition.

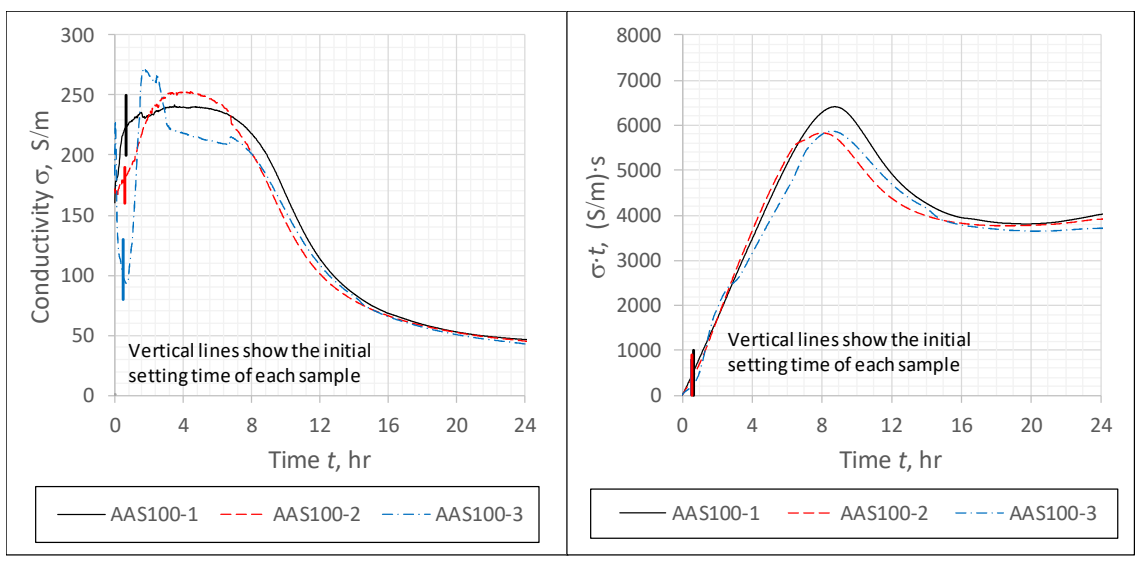

Fig. 3. Conductivity curves from the samples mixed with $100 \%$ slag.

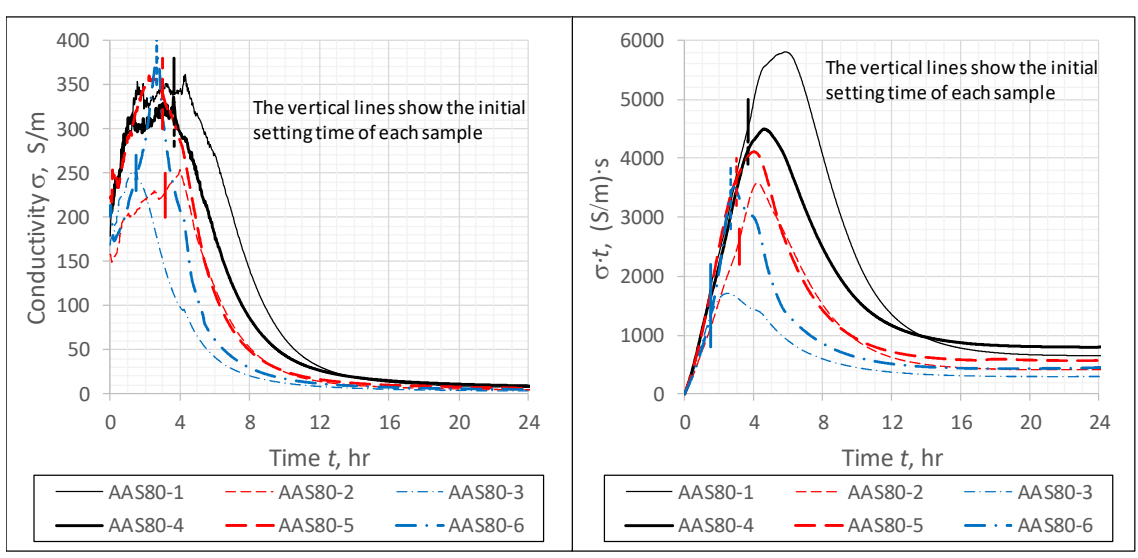

Fig. 4. Conductivity curves from the samples mixed with $80 \%$ slag and $20 \%$ cement.

Fig. 4 shows the conductivity curves recorded from the samples mixed with $80 \%$ slag and $20 \%$ cement. For samples AAS $80-3$ and AAS80-6, the peak of conductivity curve coincides with the initial setting time, but not for the other samples. The peeks of $\sigma \cdot t$ curves are, however, always behind the respective initial setting time by 1-2 hours except for sample AAS80-6, in which the peak is behind its initial setting time by only 10 minutes. Without addition of gypsum (samples AAS80-1 and AAS80-4), the 
peak appeared earlier when higher amount of $\mathrm{Na}_{2} \mathrm{O}$ was used (in sample AAS80-4), implying a stronger activation. Addition of gypsum in the mixes significantly changed the hydration process and accelerated the formation of solid network in the matrix, especially when lower amount of $\mathrm{Na}_{2} \mathrm{O}$ was used (in samples AAS80-1 to AAS80-3). This effect should be attributed to the formation of ettringite because in these mixes the $20 \%$ cement can supply adequate calcium ions. The effects of gypsum in samples AAS80-5 and AAS80-6 are not big as in samples AAS80-2 and AAS80-3, probably due to a lower solubility of gypsum in the former samples with higher amount of $\mathrm{Na}_{2} \mathrm{O}$.

\section{Concluding remarks}

From the preliminary results presented above the following concluding remarks can be given:

- The electrical resistivity or conductivity monitoring by means of Winner's fourelectrodes method indeed supplies useful information related to the hydration process.

- The test setup proposed in this study is relatively simple and can easily be built up in ordinary laboratories.

- The addition of gypsum in mixes with $100 \%$ slag has no clear effect on the hydration process, whilst the addition of gypsum in mixes with $80 \%$ slag and $20 \%$ cement significantly changed the hydration process and accelerated the formation of solid network in the matrix.

Acknowledgement This paper is part of the projects financed by Vinnova (201603367) and EU-H2020 (777823).

\section{References}

1. Provis, J.L.: Alkali-activated materials. Cem Concr Res, https://doi.org/10.1016/j.cemconres.2017.02.009 (2017).

2. AASHTO TP 95: Standard test method for surface resistivity of concrete's abil-ity to resist chloride ion penetration, American Association of State Highway and Transportation Officials, USA (2014).

3. Li, Z., Wei, X., Li, W.: Preliminary interpretation of Portland cement hydration process using resistivity measurement. ACI Mater J, May-June, 253-257 (2003).

4. Li, Z., Xiao, L., Wei, X.: Determination of concrete setting time using electrical resistivity measurement. J Mater Civ Eng, 19(5), 423-427 (2007).

5. Xiao L. and Li, Z., New understanding of cement hydration mechanism through electrical resistivity measurement and microstructure investigations. J Mater Civ Eng, 21(8), 368373 (2009).

6. Wei, X. et al., Hyperbolic method to analyze the electrical resistivity curve of Portland cement with superplasticizer. J Wuhan Uni Tech-Mater Sci ed, April, 245-248 (2008). 